\title{
Enhanced Virulence Gene Activity of Agrobacterium in Muskmelon (Cucumis melo L.) cv. 'Birdie'
}

\author{
Abul K.M.MOHIUDDIN ${ }^{1,5}$, Zaliha C ABDULLAH ${ }^{2}$, Kamal CHOWDHURY3 \\ Kulaveerasingam HARIKRISHNA4, Suhaimi NAPIS' \\ ${ }^{1}$ Mawlana Bhashani Science and Technology University, Department of Biotechnology and Genetic \\ Engineering, Santosh, Tangail-1902, Bangladesh; akmmohiu@yahoo.com \\ ${ }^{2}$ CRAUN Research Sdn. Bhd., Lot 3147, Block 14, Jalan Sultan Tengah, 93055 Kuching, Sarawak, Malaysia \\ ${ }^{3}$ Claflin University, Department of Biology, 400 Magnolia Street, Orangeburg, SC 29115, USA; kchowdhury@claflin.edu \\ ${ }^{4}$ Sime Darby Technology Centre, Biotechnology Division, 2 Jln. Tandang 46050, Petaling Jaya, Selangor D.E., Malaysia \\ ${ }^{5}$ University Putra Malaysia, Department of Biotechnology, 43400 Serdang, Selangor DE, Malaysia; suhaimi@fsb.upm.edu.my
}

\begin{abstract}
Muskmelon (Cucumis melo L.) cultivar 'Birdie', was evaluated for its response to the tumorigenic Agrobacterium tumefaciens and the oncogenic $A$. rhizogenes strains. Stem and petiole of three week-old in vitro-grown muskmelon plants were inoculated with five strains of $A$. tumefaciens and $A$. rhizogenes each and observed phenotypic expressions i.e. induction of crown galls and hairy roots. This phenotypic expression was efficaciously increased when virulence gene activity of different strains of two Agrobacterium species was enhanced. Intensive studies on enhancement of virulence gene activity of Agrobacterium found to be correlated to the appropriate light intensity $\left(39.3 \mu \mathrm{mol} \mathrm{m} \mathrm{m}^{-2}\right)$ with a specific concentration of monocyclic phenolic compound, acetosyringone $(20 \mu \mathrm{M})$. The gene activity was also influenced by several other physical factors e.g. plant tissue type, Agrobacterium species and their strains, and plant tissue-Agrobacterium interaction. Among the different $A$. tumefaciens strains, LBA4404 showed the best virulence gene activity in both stem and petiole through the formation of higher rate of crown galls. On the other hand, strain 15834 of $A$. rhizogenes showed better gene activity in stem and 8196 in petiole through the formation of higher rate of hairy roots as well as higher average number of hairy roots. Among the two different types of explants, petiole was more susceptible to both Agrobacterium species. Thus it was concluded that future muskmelon transformation study can efficiently be carried out with LBA4404, 15834 and 8196 strains using petiole explants by adding $20 \mu \mathrm{M}$ of acetosyringone in the medium.
\end{abstract}

Keywords: Agrobacterium, Muskmelon, tumorigenic and oncogenic, virulence gene, wild type

\section{Introduction}

Both Agrobacterium tumefaciens and A. rhizogenes are soil-borne pathogenic bacteria. They are able to transfer their plasmid-encoded genes (T-DNA) and virulence (vir) proteins into plant cells (Hodges et al., 2004). The T-DNA of Agrobacterium is stably integrated in the plant genomes and expressed that eventually causes crown gall or hairy root diseases (Hodges et al., 2009) and it is maintained in the plant cells in the absence of bacteria (Chilton et al., 1977). This novel method is utilized as an efficient and excellent technique in plant genetic transformation study in many laboratories (Boyko et al., 2009).

Success in plant genetic transformation through Agrobacterium-mediated method depends on the virulence of strain(s) of $A$. tumefaciens and $A$. rhizogenes to a particular plant species concern (Machado et al., 1997). In many cases, Agrobacterium is found to be less virulent or less susceptible to infection of a particular plant species or explant indicating poor transformation efficiency or no transformation (Mohiuddin et al., 2009). A high degree of virulence means that plants are more susceptible to infection and totipotency of infectious cells improves transformation efficiency to produce transgenic plants (Boyko et al., 2009). Many $A$. tumefaciens and $A$. rhizogenes strains are more virulent in transgene integration on explants from some plant species than on others (Draper et al., 1988). Therefore, the isolation of virulent or super virulent strains of $A$. tumefaciens and $A$. rhizogenes and their improvement of virulence gene activity study is important to facilitate the transformation in recalcitrant plant species containing biotic and abiotic stress tolerant gene(s).

The crown gall and hairy root diseases are produced by the specific action of integration and expression of the bacterial gene in plant genomes (Hodges et al., 2009). A crown gall is produced in plants by the wild-type $A$. tumefaciens in all situations where the transferred Ti (Tumour inducing) plasmid vector has virulence (vir) and oncogen- 
72

ic (onc) genes and hairy roots are produced by wild type $A$. rhizogenes strains containing the $\mathrm{Ri}$ (root inducing) plasmid (Drapper et al., 1988; Smith and Townsend, 1907; Hopkins and Durbin, 1971). Host limitation is a drawback of both Agrobacterium species hence unable to transfer its T-DNA to all plant species concern (Cleene and Ley, 1976, 1981); however, it can be overcome through the application of chemical compounds, results in activation of vir gene leading to the processing of its T-DNA from the Ti-plasmid and transfer to recipient host cells (Gelvin, 2006). For the last few years some Agrobacterium infection works have been carried out on muskmelon (Matsumoto et al., 1986) and also in many other plant species i.e. lotus (Jian et al., 2009), Brassica sp. (Kong et al., 2009) and garlic (Kenel et al., 2010). The present study was carried out to enhance the vir gene activity of different wild type Agrobacterium species through the application of chemical compounds along with physical factors and evaluate the vir gene activity through the phenotypic expression i.e. formation of crown galls or hairy roots on muskmelon cultivar 'Birdie'.

\section{Materials and methods}

\section{Seedling germination}

Seeds of the muskmelon (Cucumis melo L.) cultivar 'Birdie' (Sakata Seed Corporation, Japan) were used for this present study. Seeds were soaked in distilled water for approximately 10-20 minutes and the testa removed manually. The decoated seeds (with endotesta) were treated with $70 \%$ denatured ethanol for one minute, and then surface sterilised by a solution of $20 \%$ (v/v) Clorox, a commercial bleach containing $5.25 \%$ sodium hypochlorite, with 6 drops (per liter) of Tween 20 [polyoxyethylene (20) sorbitan monolaurate, Sigma, USA] for 15 minutes (Tabei et al., 1991). Seeds were then washed 3-4 times, with sterile distilled water.

Healthy and unwrinkled seeds were sorted and germinated (one seed per box) aseptically in Magenta boxes (GA 7, 110-mm height, USA) on hormone free MS (Murashige and Skoog, 1962) full strength basal medium (MSO) supplemented with $2 \%$ phytagel (Sigma, USA). The medium was adjusted to $\mathrm{pH} 5.7$ before autoclaving at $121^{\circ} \mathrm{C}$ for 15 $\min$ at $1.05 \mathrm{Kg} / \mathrm{cm}^{-2}$ pressure (15-20 psi). Magenta boxes were sealed with semi-transparent and moisture-resistant Parafilm $^{\mathrm{R}}$ (Sigma, USA). The seeds were incubated for one day at $26 / 27^{\circ} \mathrm{C}$ in a dark chamber to ensure uniform and rapid germination (Trulson and Shahin, 1986). The germinated seeds were subsequently transferred to an incubation room at $24 \pm 1^{\circ} \mathrm{C}$ for elongation under $16 \mathrm{~h}$ photoperiod of $39.3 \mu \mathrm{mol} \mathrm{m}-^{2} \mathrm{~s}^{1}$ light intensity provided by cool-white fluorescent and incandescent lights.

\section{Media for Agrobacterium culture}

LB (Luria-Bertani) medium (broth) was prepared using 1\% Bacto-peptone, 0.5\% Bacto-yeast extract and 1\%
$\mathrm{NaCl}$ (w/v) for wild type $A$. tumefaciens culture. Similarly, for $A$. rhizogenes YMB medium (Yeast Mannitol Broth) containing $\mathrm{K}_{2} \mathrm{HPO}_{4}, 2 \mathrm{H}_{2} \mathrm{O}(0.5 \mathrm{~g} / \mathrm{l}), \mathrm{MgSO}_{4}, 7 \mathrm{H}_{2} \mathrm{O}(0.2$ $\mathrm{g} / \mathrm{l}), \mathrm{NaCl}(0.1 \mathrm{~g} / \mathrm{l})$ yeast extract $(0.4 \mathrm{~g} / \mathrm{l})$ and mannitol $(10.0 \mathrm{~g} / \mathrm{l})$ was prepared. The both media were adjusted to $\mathrm{pH} 7.2$ before autoclaving at $121^{\circ} \mathrm{C}$ for $15 \mathrm{~min}$ at $1.05 \mathrm{Kg} /$ $\mathrm{cm}^{-2}$ pressure (15-20 psi). For YMB medium-mixture (i) $\mathrm{K}_{2} \mathrm{HPO}_{4}, \mathrm{NaCl}$, yeast extract and mannitol mixture (ii) $\mathrm{MgSO}_{4}, 7 \mathrm{H}_{2} \mathrm{O}$ were autoclaved separately. Five tumorigenic strains of $A$. tumefaciens and five oncogenic strains of $A$. rhizogenes were cultured in tubes with freshly prepared LB and YMB media, respectively and agitated at 150-175 rpm overnight at $27^{\circ} \mathrm{C}$ (Mihaljevic et al., 1996). The optimal density (OD) of each overnight-cultured Agrobacterium strain was monitored by UV spectrophotometer and selected as 0.6 for inoculation.

\section{Agrobacterium strains}

Five tumorigenic $A$. tumefaciens strains e.g. LBA4404, A737, C58, A348, and A281 and five oncogenic $A$. rhizogenes strains e.g. 9402, 15834, A4, 8196 and A105, collected from Rubber Research Institute of Malaysia, were used for susceptibility test and increase their virulence (vir) gene activity through inoculation of seedlings of muskmelon cv. 'Birdie'.

\section{Muskmelon tissue and inoculation}

Stem and petiole of three week-old in vitro-grown muskmelon plants (20 in each) were inoculated with each strain of $A$. tumefaciens and $A$. rhizogenes. Stem and petiole of each plant were aseptically wounded by a sterile scalpel blade and the wound sites were inoculated with freshly prepared (tumorigenic and oncogenic) A. tumefaciens and A. rhizogenes strains, respectively, using a sterile needle. Twenty plants of muskmelon were inoculated with each Agrobacterium strain $(\mathrm{OD}=0.6)$ for each explants (stem and petiole) in each treatment. A total of 600 plants (20 plants $x 10$ strains $x 3$ treatments) were inoculated

\section{Incubation conditions}

Inoculated plants were pre-incubated for two days in a dark chamber at $24 \pm 1^{\circ} \mathrm{C}$ for uniform growth (Trulson and Shahin, 1986) and then 200 plants (20 plants x 10 strains) transferred into a culture room maintained at same temperature with $16 \mathrm{~h}$ light $\left(39.3 \mu \mathrm{mol} \mathrm{m} \mathrm{m}^{-2}\right) / 8$ h dark treatment. Two sets of 200 plants ( 20 plants $x 10$ strains) were incubated into the same culture room with two different light intensity e.g. $55.0 \mu \mathrm{mol} \mathrm{m}^{-2} \mathrm{~s}^{-1}$ and 23.6 $\mu \mathrm{mol} \mathrm{m} \mathrm{m}^{-1}$ provided by cool-white fluorescent and incandescent lamps. A subset of those explants which initiated callus from the infected sites but had not formed crown galls or hairy roots at $39.3 \mu \mathrm{mol} \mathrm{m} \mathrm{m}^{-1}$, were also incubated under $16 \mathrm{~h}$ photoperiod with $55.0 \mu \mathrm{mol} \mathrm{m}^{-2} \mathrm{~s}^{-1}$ and 23.6 $\mu \mathrm{mol} \mathrm{m} \mathrm{m}^{-2}$ light intensity. Three weeks later, crown galls and hairy roots were separated from infected plants and cultured onto both hormone free MS medium containing 
$500 \mathrm{mg} / \mathrm{l}$ cefotaxime and MS medium containing 0.1 and $0.3 \mathrm{mg} / 1$ 2,4-D in combination with $500 \mathrm{mg} / \mathrm{l}$ cefotaxime. The cultures were incubated in the same culture room under $16 \mathrm{~h}$ light $\left(39.3 \mu \mathrm{mol} \mathrm{m}^{-2} \mathrm{~s}^{-1}\right) / 8 \mathrm{~h}$ dark treatment. Twenty replicates of crown galls and hairy roots were used for each experiment.

\section{Dark incubation}

A subset of those explants which initiated callus from the infected sites after inoculation but had not formed crown galls or hairy roots, were incubated under continuous dark condition at $24 \pm 1^{\circ} \mathrm{C}$.

\section{Acetosyringone concentrations}

Both wild type $A$. tumefaciens and $A$. rbizogenes strains were further cultured into LB and YMB media, respectively, and four different concentrations of acetosyringone e.g. $10,20,40$ and $100 \mu \mathrm{M}$ added separately to the media one hour before inoculation. The stem and petiole of muskmelon were then inoculated by the same wild type Agrobacterium strains, grown in media containing acetosyringone, and incubated at $24 \pm 1^{\circ} \mathrm{C}$ under $16 \mathrm{~h}(39.3 \mu \mathrm{mol}$ $\left.\mathrm{m}^{-2} \mathrm{~s}^{-1}\right) / 8 \mathrm{~h}$ light/dark treatment. Twenty replicates were used for each experiment with particular treatment. A total of 800 plants ( 20 plants $\mathrm{x} 10$ strains $\mathrm{x} 4$ acetosyringone concentrations) were tested.

\section{Statistical analysis}

A completely randomised design (CRD) was used for all experiments. Descriptive statistics such as mean and standard error were used for percentage of crown gall and hairy root induction as well as the average number of hairy roots produced from petiole and stem explants of muskmelon species.

\section{Results}

\section{Effect of A. tumefaciens strains on phenotypic expression} (crown-gall induction)

Seedlings of muskmelon inoculated with different virulent strains of $A$. tumefaciens in in vitro condition developed callus at the site of infection within 7 to 8 days, and crown gall development from the callus was initiated after 2 to 3 days. The crown galls were observed in both stems and petioles at $16 / 8 \mathrm{~h}$ light $\left(39.3 \mu \mathrm{mol} \mathrm{m}^{-2}\right.$ $\left.s^{-1}\right) /$ dark treatment. Stems of muskmelon were found less susceptible than petioles to $A$. tumefaciens. The virulence gene of $A$. tumefaciens strains, LBA4404, A737, C58 and A348 were capable of inducing crown galls in muskmelon plants. However, the strain types of $A$. tumefaciens strains influenced the efficiency of crown gall induction in stem and petiole explants of muskmelon (Fig. 1). Among the $A$. tumefaciens strains tested in this study, only A281 strain failed to induce crown galls in muskmelon plants and they died within few weeks of inoculation. The colour of the muskmelon stem-derived calluses were white (Fig. 12a).

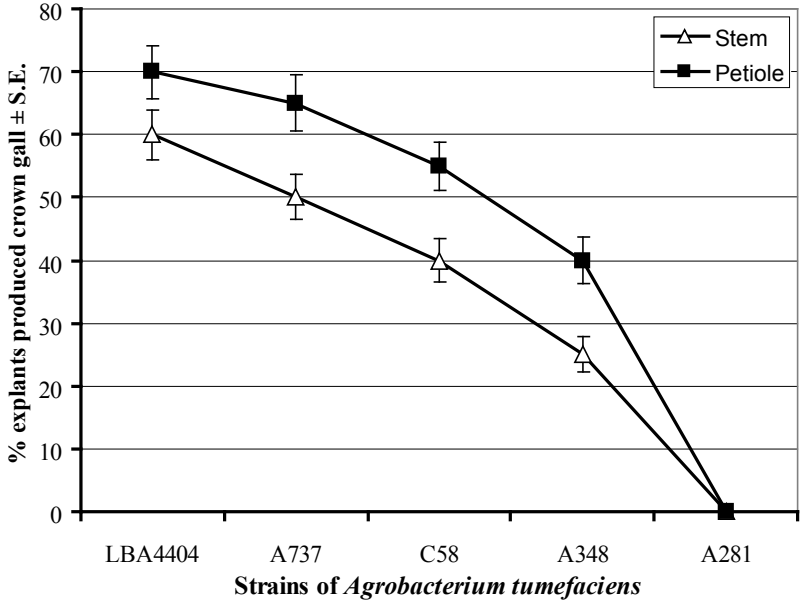

Fig. 1. Strain-dependent variation in crown gall induction on muskmelon explants at $39.3 \mu \mathrm{mol} \mathrm{m}^{-2} \mathrm{~s}^{-1}$

The best results of crown gall induction were seen in the petiole explants, seeing that the crown galls were formed in 25 to $60 \%$ of muskmelon stem and 40 to $70 \%$ petiole explants, respectively (Fig. 1). Among the five different strains of $A$. tumefaciens tested in this study, the virulence genes of strain LBA 4404 was highly infectious to both explants of muskmelon. This strain was capable of inducing crown galls from $60 \%$ and $70 \%$ of infected stem and petiole explants of muskmelon, respectively (Fig. 1). On the other hand, the virulence gene of strains A348 and C58 were less infectious to muskmelon explants compared to LBA4404 (Fig. 1).

\section{Effect of A. rhizogenes strains on phenotypic expression (hairy root induction)}

All five A. rhizogenes strains $(8196,15834,9402$, A4 and A105) tested in this study induced hairy roots production from the infected/inoculated sites of muskmelon (stem and petiole) at $16 / 8 \mathrm{~h}$ light $\left(39.3 \mu \mathrm{mol} \mathrm{m}-{ }^{2} \mathrm{~s}^{-}\right) /$dark treatment. Gene virulence of $A$. rhizogenes strains 8196 and 15834 was more effective in the petioles, whereas 8196,15834 and 9402 strains were more effective in the stem explants (Fig. 2). Most of the muskmelon stems and petioles inoculated with virulent strains of $A$. rhizogenes developed callus growth at the site of infection within 7 to 8 days, and hairy root development from the callus was initiated 3 to 4 days later. The appearance of induced hairy roots from muskmelon stem is illustrated in Fig. 12b.

The virulence gene of all $A$. rbizogenes strains showed phenotypic expression in 15 to $70 \%$ of muskmelon explants in the form of adventitious hairy roots formation (Fig. 2). Among the five different strains of $A$. rhizogenes the virulence gene of strain 8196 and 15834 were highly effective to both the stem (Fig. 12c) and petiole of muskmelon. These strains were capable of inducing hairy roots from nearly $65 \%$ of stems and petioles. On the other hand, similar level of expression of virulence genes of strain 9402 was observed in stem only. Therefore, the strain 8196 will 
74

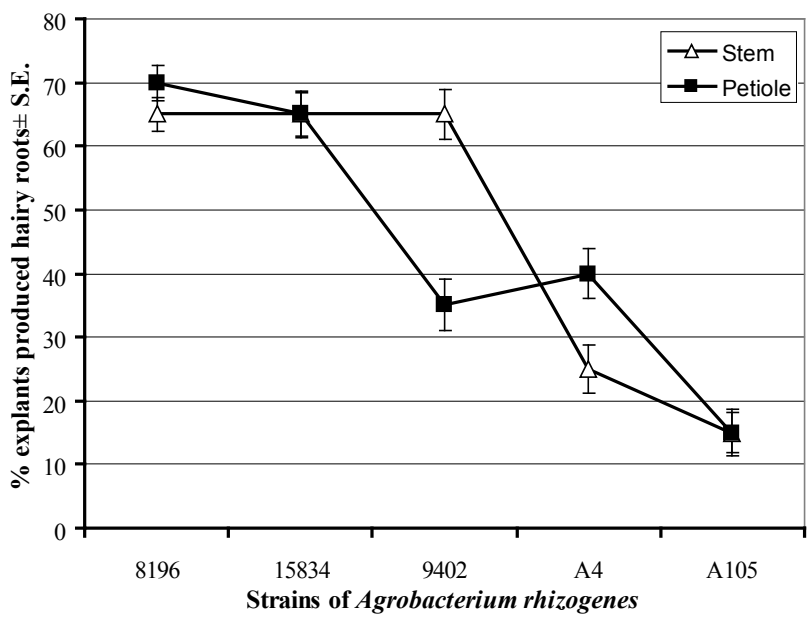

Fig. 2. Strain-dependent variation in hairy root induction on muskmelon explants at $39.3 \mu \mathrm{mol} \mathrm{m} \mathrm{s}^{-1}$

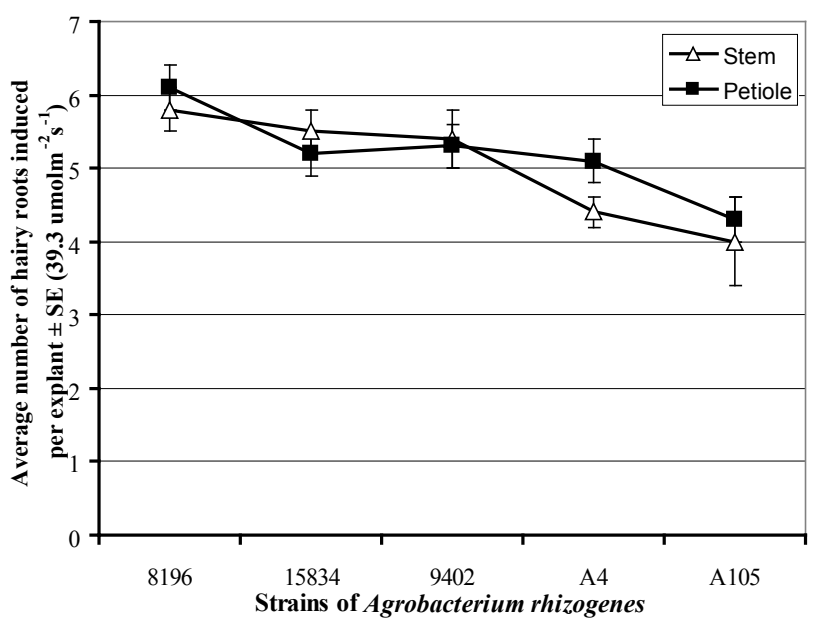

Fig. 3. Strain-dependent variation in number of hairy root induction on muskmelon explants

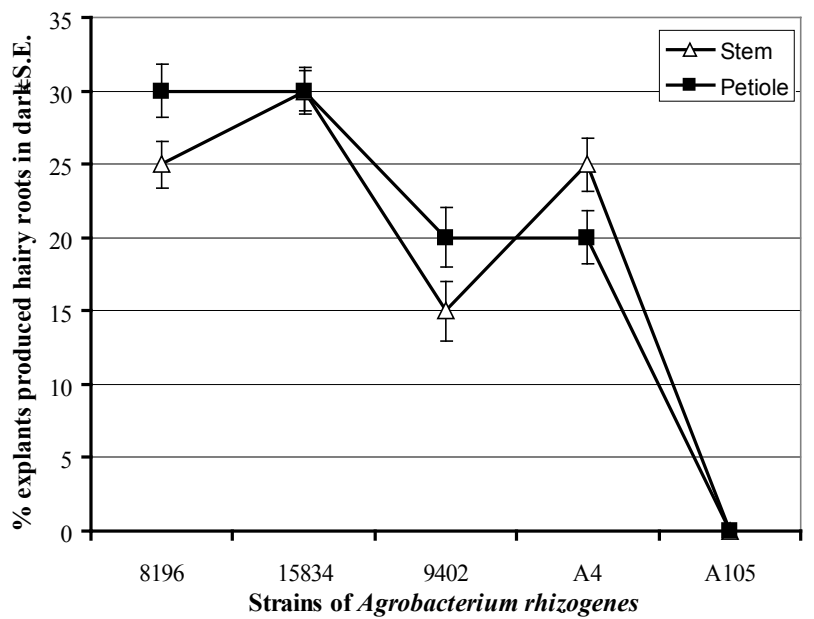

Fig. 4. Strain-dependent variation in hairy root induction in the dark on muskmelon explants be most suitable for transformation study using petiole explant. Similarly, strain 8196, 15835 and 9402 will be also suitable for transformation study using stem explant. The A105 strain was least effective (15\%) in inducing hairy roots in muskmelon stem and petiole (Fig. 2).

The types of $A$. rhizogenes strains used in this study influenced the production of numbers of hairy roots from muskmelon stem or petiole when inoculated at $39.3 \mu \mathrm{mol}$ $\mathrm{m}^{-2} \mathrm{~s}^{-1}$ (Fig. 3). The strain 8196 was highly virulent and induced an average of 5.8 and 6.1 hairy roots from muskmelon stem and petiole, respectively. The other strains were less virulent and induced lower numbers of hairy roots from stem and petiole explants (Fig. 3). However, the difference among the strains 8196, 15834 and 9402 was not statistically significant.

\section{Effect of light intensity on crown-gall and hairy root induction}

Among the three light intensities treatment tested $\left(23.6 \mu \mathrm{mol} \mathrm{m} \mathrm{s}^{-2}, 39.3 \mu \mathrm{mol} \mathrm{m} \mathrm{s}^{-1}\right.$ and $\left.55.0 \mu \mathrm{mol} \mathrm{m}^{-2} \mathrm{~s}^{-1}\right)$ only $39.3 \mu \mathrm{mol} \mathrm{m}^{-2} \mathrm{~s}^{-1}$ was suitable for inducing crown gall or hairy roots from stem and petiole of muskmelon (data not shown).

\section{Effect of dark incubation on crown-gall and hairy root} induction

Under continuous dark condition, only two out of five strains of $A$. tumefaciens tested in this study (LBA 4404 and A737) were able to form crown galls in muskmelon. However, the response expressed as percentage was much lower compared to under $16 \mathrm{~h}$ light $\left(39.3 \mu \mathrm{mol} \mathrm{m}^{-2} \mathrm{~s}^{-1}\right)$ $15 \%$ in stem and $25 \%$ in petiole (data not shown). Moreover, the galls induced under dark conditions were smaller in size in comparison to galls induced under $16 \mathrm{~h}$ light $\left(39.3 \mu \mathrm{mol} \mathrm{m}^{-2} \mathrm{~s}^{-1}\right)$ condition. The other three strains did not produce any crown gall in muskmelon stem or petiole incubated under continuous dark.

Similarly, lower number of muskmelon explants produced hairy roots under dark conditions (Fig. 4) compared to the explants exposed under $16 \mathrm{~h}$ light $(39.3 \mu \mathrm{mol}$ $\mathrm{m}^{-2} \mathrm{~s}^{-1}$ ) incubation (Fig. 2).

The A105 strain of $A$. rhizogenes failed to produce hairy roots when incubated under dark condition (Fig. 4, 5). Although the other four $A$. rhizogenes strains 8196 , 15834, 9402 and A4 produced hairy roots in muskmelon stem and petiole, their response rate were less than half of that was observed under under $16 \mathrm{~h}$ light $\left(39.3 \mu \mathrm{mol} \mathrm{m}^{-2}\right.$ $\mathrm{s}^{-1}$ ). Moreover, the number of hairy roots produced by the four strains in the dark condition was approximately $25 \%$ leass than that of under $16 \mathrm{~h}$ light $\left(39.3 \mu \mathrm{mol} \mathrm{m}^{-2} \mathrm{~s}^{-1}\right)$ condition (Fig. 5).

\section{Effect of acetosyringone on crown gall formation}

Although the $A$. tumefaciens strain A281 failed to induce crown gall in stem and petiole of muskmelon (Fig. 1) the same strain was able to induce crown galls in stem and 
75

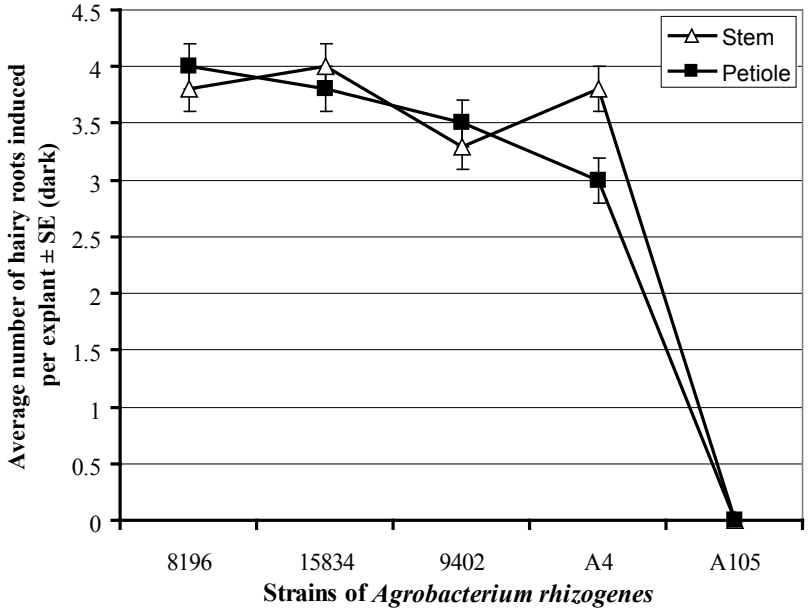

Fig. 5. Effect of dark factor on number hairy root induction in muskmelon explants

petiole of muskmelon after acetosyringone was added in LB medium (Fig. 6 and 7). Among the four acetosyringone concentrations tested, $20 \mu \mathrm{M}$ was most effective in enhancing crown gall induction from both stem and petiole of muskmelon compared to the control (Fig. 1) followed by 40 and $100 \mu \mathrm{M}$ concentrations (Fig. 6 and 7). Similarly, A348 that had grown with $40 \mu \mathrm{M}$ acetosyringone induced bit higher percent of crown gall (45\%) (Fig. 7) than control (40\%) (Fig.1). Acetosyringone at the concentration of $10 \mu \mathrm{M}$ was also found in our study ineffective or less effective (data not shown) as 40 and $100 \mu \mathrm{M}$.

LBA4404 strain together with $20 \mu \mathrm{M}$ acetosyringone promoted the greatest crown gall induction in stem and petiole of muskmelon e.g. $75 \%$ and $85 \%$, respectively (Fig. 6 and 7). The other virulent strains of $A$. tumefaciens (A737, C58, A348 and A281) that had grown in the same concentration $(20 \mu \mathrm{M})$ also promoted crown galls induction in stem e.g. $60 \%, 50 \%, 35 \%$ and $15 \%$, respectively that was approximately $10 \%$ higher than the control (Fig. 1 and 6). Similar result was also observed with petiole when $A$.

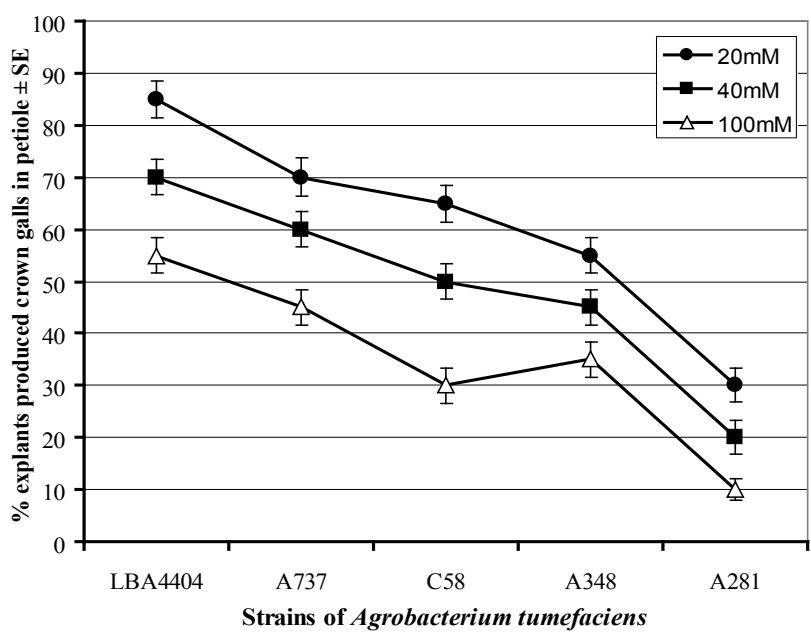

Fig. 6. Effect of acetosyringone conc. on crown gall induction in stem of muskmelon

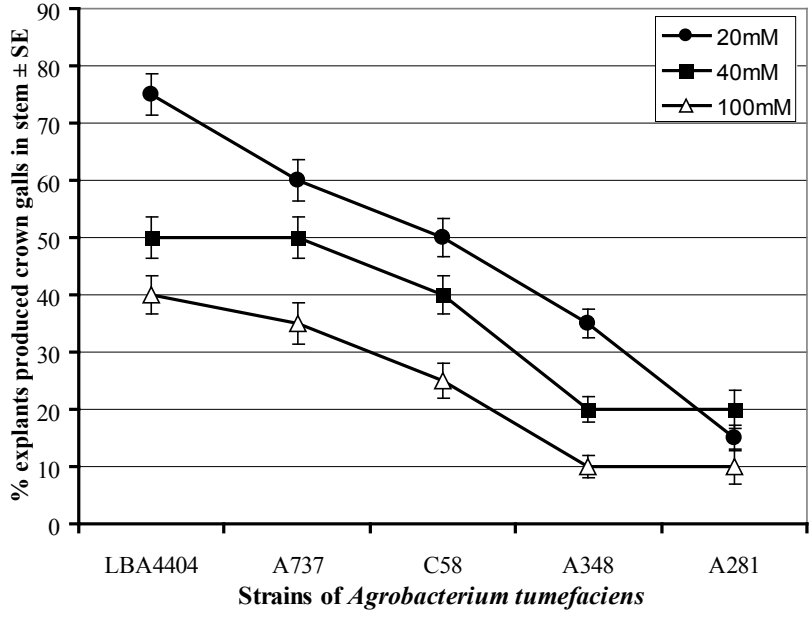

Fig. 7. Effect of acetosyringone on crown galls induction in petiole of muskmelon

tumefaciens strains had grown with acetosyringone $20 \mu \mathrm{M}$ (Fig. 1 and 7). The two other concentrations of acetosyringone that had supplemented all $A$. tumefaciens strains except A281 reduced crown gall production from both explants (Fig. 1, 6 and 7). The LBA4404 strain had a perform consistently better than the other four $A$. tumefaciens strains tested in this study for crown gall induction both from stem and petiole in the presence or absence of acetosyringone (Fig. 1, 6 and 7).

\section{Effect of acetosyringone on hairy root induction}

The percent hairy root induction per wound site was also enhanced (approximately 23\% higher) when infected by $A$. rhizogenes strains grown in YMB medium containing $20 \mu \mathrm{M}$ of acetosyringone (Fig. 8 and 9) and compared to the control (Fig. 2). However, the other two concentrations $(40 \mu \mathrm{M}$ and $100 \mu \mathrm{M})$ of acetosyringone tested did not show a better result (Fig. 2, 8 and 9). The strains 15834 and 8196 showed approximately 30\% higher hairy roots production response in both stem and petiole of

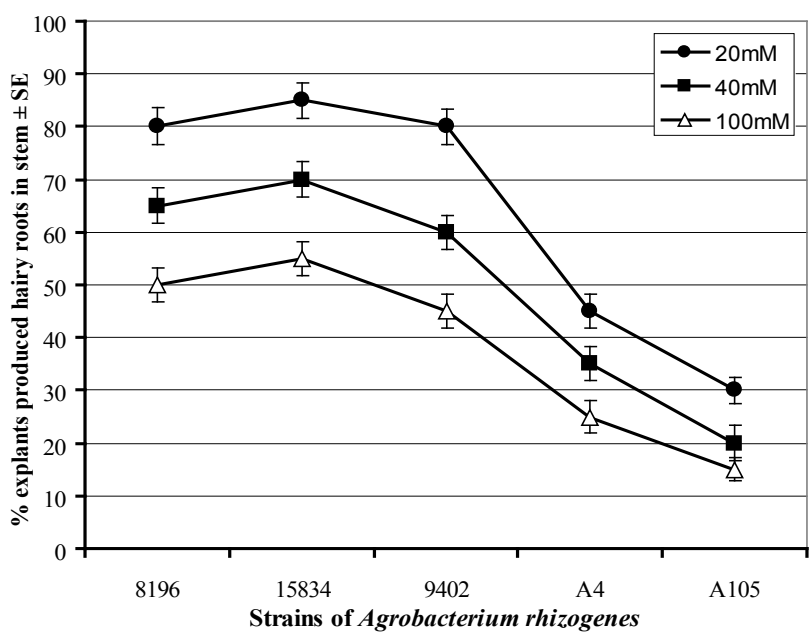

Fig. 8. Effect of acetosyringone on induction of hairy roots in stem of muskmelon 
76

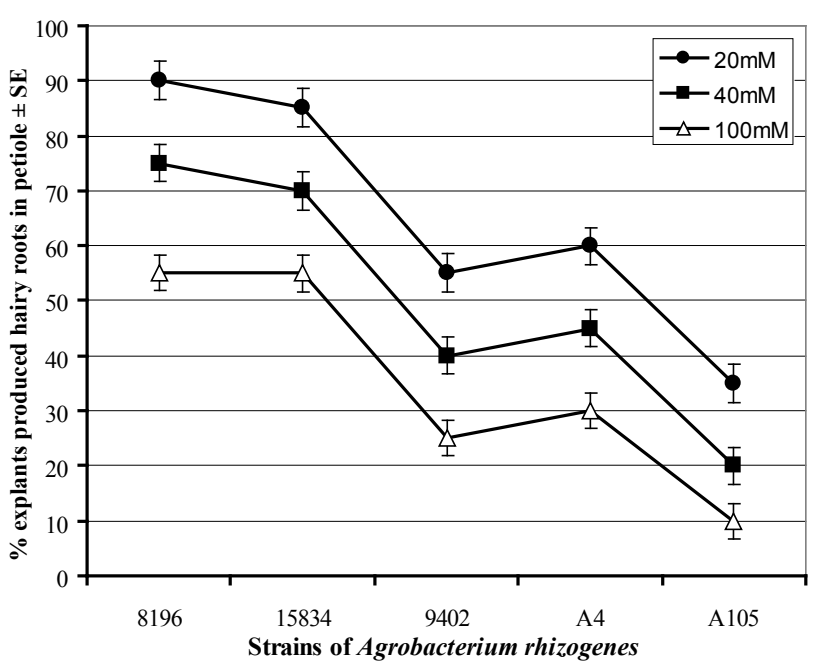

Fig. 9. Effect of acetosyringone on induction of hairy roots in petiole of muskmelon

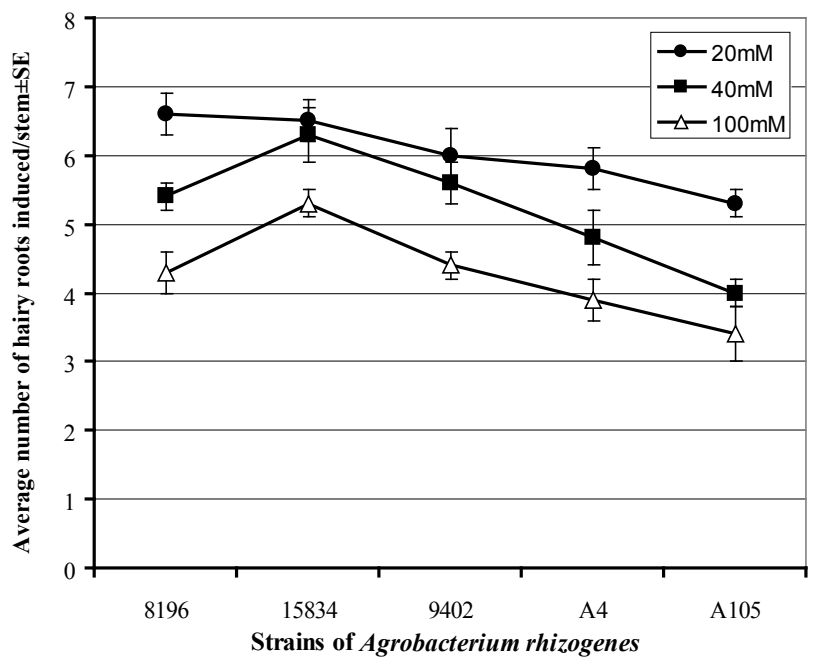

Fig. 10. Effect of acetosyringone on number of hairy roots induced in stem of muskmelon

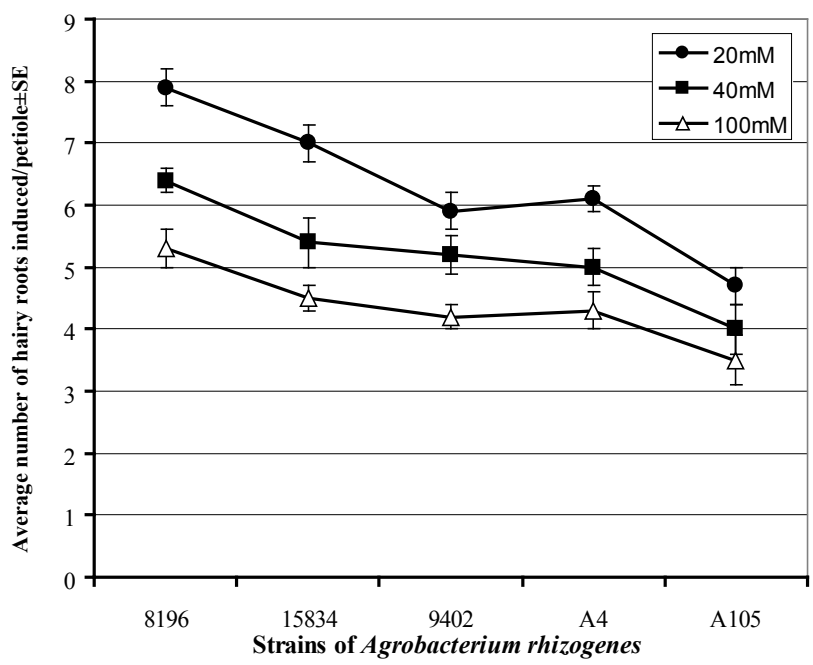

Fig. 11. Effect of acetosyringone on number of hairy roots induced in petiole of muskmelon muskmelon with the treatment with YMB medium plus $20 \mu \mathrm{M}$ acetosyringone when compared to the control (Fig. 2, 8 and 9). It was also observed an increase over 20\% in the number of hairy roots in both stem and petiole of muskmelon when A. rhizogenes strains 15834 and 8196 had grown in YMB medium containing $20 \mu \mathrm{M}$ of acetosyringone (Fig. 3, 10 and 11).

\section{Discussion}

After the inoculation a variable time period is required for transferring T-DNA from $A$. tumefaciens to the plant cells and to produce callus. Matsumoto et al. (1986) also reported similar results for the same phenotypic expression i.e. crown gall production. These variations may be related to some steps/factors applied and the results obtained on crown gall induction suggest that the virulence gene activity of A. tumefaciens in the form of crown gall production in muskmelon tissue (stem or petiole) is strongly affected by several factors as the $A$. tumefaciens strains, tissue type, plant tissue-Agrobacterium interaction and light intensity. Similar effects have been observed in other plant species, e.g. Eucalyptus (Machado et al., 1997) and lentil (Hassan et al., 2007). Better gall induction was found in petiole when compared to stem clearly demonstrating that petiole is more susceptible to virulent gene of $A$. tumefaciens and could be used for future gene transformation study.

The findings reported in the present research showed that the A. tumefasciens LBA4404, A373 and C58 strains have relatively high virulence activities. Similar expression of C58 strain was also observed in soybean (Delzer et al., 1990). Our observation confirmed that LBA4404 strain is most suitable for muskmelon transformation study. This strain found suitable for successful transformation study in many other crops such as potato with $58.4 \%$ of internode explants (Sarker et al., 2009) and garlic (Kenel et al., 2010). Different rates of crown gall induction obtained from the same explant, inoculated with different A. tumefaciens strains evidently suggest that the rates of tumorigenicity are strain-dependent. Delzer et al. (1990) and Katavic et al. (1991) found similar differences in soybean and pumpkin, respectively when different strains of A. tumefaciens were tested. On the other hand, it is likely that the strain A281 may be not so virulent to muskmelon plants and died in the medium due to lack of adequate nutrients.

The results in the form of hairy root induction in muskmelon tissue suggested that the virulence gene activity of A. rhizogenes is also dependent on different physical factors such as the $A$. rhizogenes strain, plant tissue type, tissue- $A$. rhizogenes strain interaction and light intensity. The effects of physical factors were also reported in many other crops like pumpkin (Katavic et al., 1991), pine (McAfee et al., 1993) and tobacco (Kumar et al., 2006). The variation in virulence gene activity in stem and petiole is different. It is not clear why this discrepancy for hairy root induction 


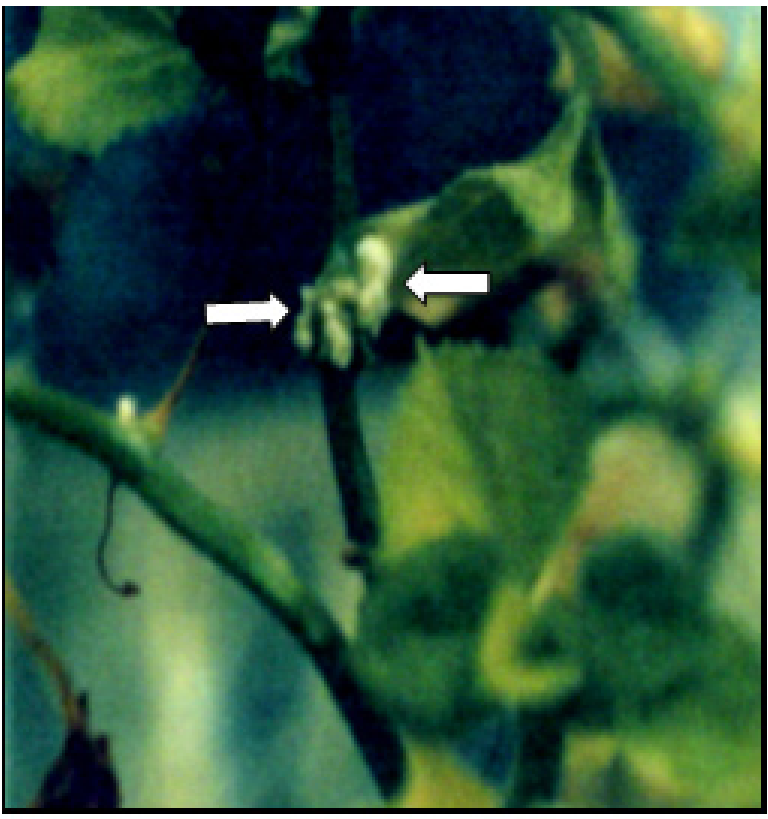

a

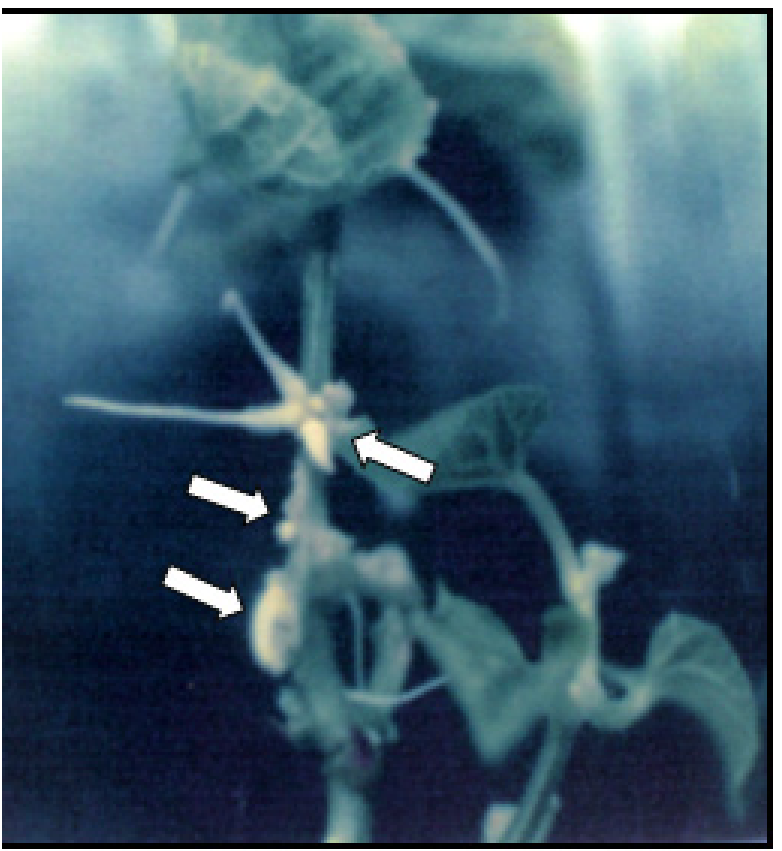

c

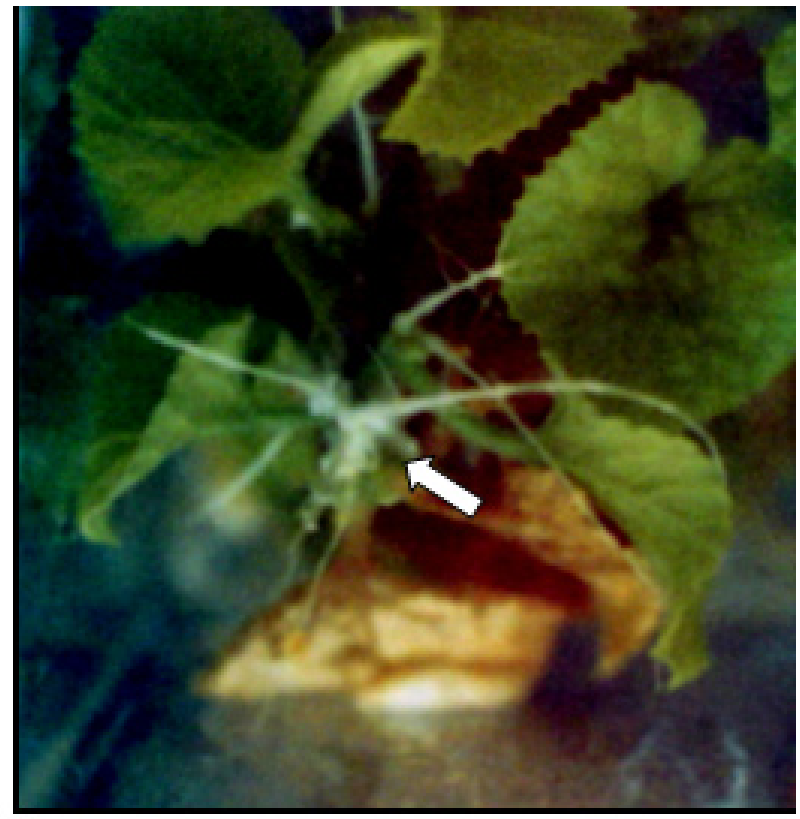

b

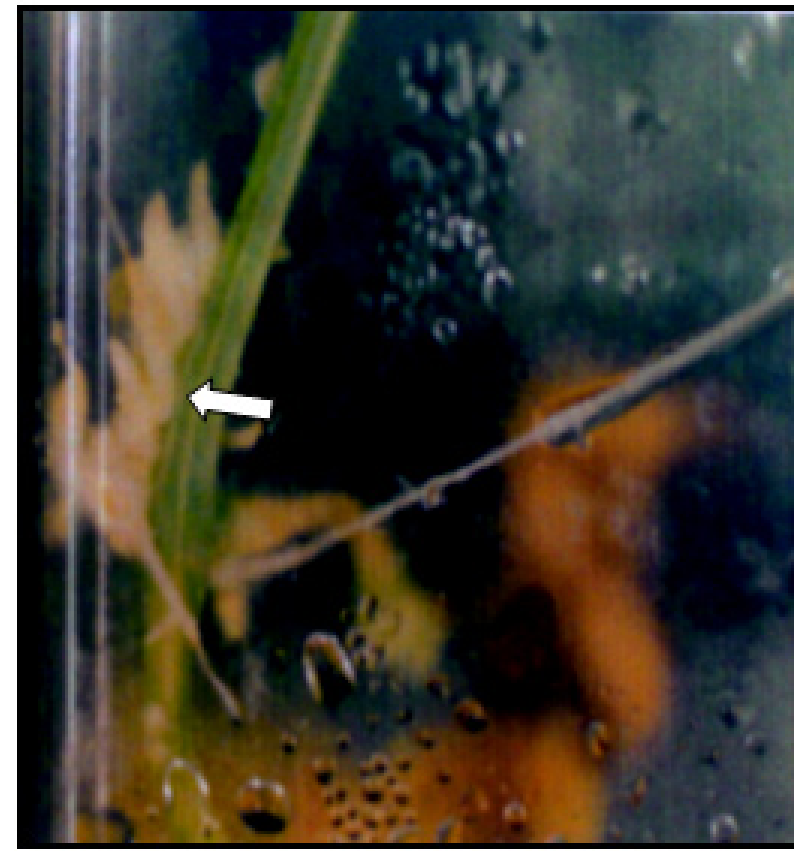

d

Fig. 12. Phenotypic expression of virulence gene of Agrobacterium in muskmelon: a) Crown galls initiated from wound site (stem) when infected with LBA 4404 strain; b) Hairy roots initiated from infected stem by $A$. rhizogenes strain A 105 at $39.3 \mu \mathrm{mol} \mathrm{m} \mathrm{m}^{-2} \mathrm{~s}^{-1}$ c) Hairy roots initiated when infected with $A$. rhizogenes strain 8196 ; d) Hairy roots instigated from stem vigorously when inoculated with $A$. rhizogenes strain 8196 in addition of acetosyringone at the concentration of $20 \mu \mathrm{M}$

exists, however it could be due to some form of interaction between the $A$. rhizogenes strain and the tissue type of the explant. Future studies could reveal the reason behind it. For hairy root initiation also, a few days is critical. Matsumoto et al. (1986) reported that a time period is crucial to release DNA from Agrobacterium to plant cells as well as its phenotypic expression.
The strains 8196, 15834, and 9402 showed comparatively high virulence activity; therefore the competent cells of stem and petiole visibly expressed and formed hairy roots. Kumar et al. (2006) observed similar result with A4 strain when infected tobacco leaf tissue. The variation in the percentage of hairy root induction in same explant (stem or petiole) inoculated with different strains evident- 
78

ly suggests that the rate of oncogenecity are dependent on the strains of $A$. rbizogenes. The findings based on induction of higher number of hairy roots confirm that 8196 is most suitable compared to others. On the other hand, the strain A105 induced lowest number of hairy roots in both stem and petiole indicates that this strain is less virulent.

The root induction response difference due to different light intensity indicates that the light intensity plays an important role for activation of virulence gene or for the synthesis of some essential compound important for the gene activity. This may be due to the alteration of the rooting environment due to hormonal or other secretions during the incubation of infected explants at the optimal light intensity. The importance of appropriate light intensity is also evident from the negative role of continuous darkness in the production of crown galls and hairy roots in muskmelon.

The findings pointed out to, in addition to the importance of the specific concentration of acetosyringone $(20$ $\mu \mathrm{M})$ that this has played a role in enhancement of virulence gene activity of all $A$. tumefaciens strains resulting in an increase in crown gall induction in both stem and petiole explants. Hess et al. (1991) reported that this phenolic compound must be constant for both biological activities of vir gene expression as well as for the expression maintenance of vir gene. Many other reports also pointed out that the vir genes are inducible in response to the monocyclic phenolic compound like acetosyringone (Parke et al., 1987; Ashby et al., 1988; Shaw et al., 1988). The results obtained with the higher and lowest concentrations of acetosyringone $(10,40$, and $100 \mu \mathrm{M})$ indicated an inhibitory action rather than stimulatory. Similar result was also observed by Kumar et al. (2006) in tobacco with high concentration of acetosyringone. The importance of acetosyringone in vir gene induction is further confirmed from the response of $A$. tumefaciens strains A281, which failed to form crown galls in stem or in petiole but was able to induce crown galls when grown with acetosyringone at three different concentrations e.g. 20, 40 and $100 \mu \mathrm{M}$. The findings of different $A$. tumefaciens strains on crown gall induction suggest that LBA4404 strain is most virulent for both stem and petiole of muskmelon. It also indicates that interaction between specific concentration of acetosyringone and $A$. tumefaciens strain played very important role in enhancement of virulence gene activity.

The crucial role of specific concentration of acetosyringone in enhancement of virulence gene activity was also evident from the increased qualitative and quantitative response of all A. rhizogenes strains in hairy root production in both stem and petiole of muskmelon. Higher percent hairy root induction by 15834 strain in stem and by 8196 strain in petiole indicated that the interaction between specific concentration of acetosyringone $(20 \mu \mathrm{M})$ and $A$. rhizogenes strain played crucial role in enhancement of virulence gene activity. The above finding suggested that these two strains could be tested in future transformation study with other Cucurbitaceae species.

The hairy roots induced from both explants of muskmelon elongated with profuse branches on hormone free MS medium containing cefatoxime however, on MS medium with 2, 4-D the roots initiated callus, which did not grow further. Similar result was also shown in crown gall. These findings confirmed that these crown gall and hairy root tissues had been transformed by T-DNA containing virulence gene and could synthesise hormones that played an accessory role in root and gall induction. Profuse branching of hairy roots in hormone free medium confirmed the subsequent selection of transformed roots (Christey and Braun, 2005; Srivastava and Srivastava, 2007) that justified the present results. The genes for hormone synthesis are found within the T-DNA of agrobacteria (White $e t$ al., 1985) and any external hormone(s) may be deleterious to this process.

\section{Conclusions}

The present study confirmed that both physical and chemical factors, mainly accurate light intensity (39.3 $\mu \mathrm{mol} \mathrm{m} \mathrm{m}^{-2} \mathrm{~s}^{-1}$ ) and the appropriate acetosyringone concentarion $(20 \mu \mathrm{M})$, together with the specific strains of Agrobacterium tumefaciens (LBA4404) and A.rbizogenes (8196 and 15834) played vital role in the enhancement of virulence gene (vir) activity in both stem and petiole of muskmelon, cv. 'Birdie'. This finding will provide valuable information in future transformation study with recalcitrant species and also a valuable contribution for a betterment of breeding program.

\section{Acknowledgement}

The authors articulate special thanks to the Rubber Research Institute of Malaysian (RRIM) for kind gift of Agrobacterium strains. Sincere thanks to the Ministry of Science, Technology and the Environment of Malaysia for providing financial support in the form of Graduate Assistantship (IRPA grant No. UPM-51267) to AMMM.

\section{References}

Ashby AM, Watson MD, Loake GJ, Shaw CH (1988). Ti plasmid-specified chemotaxis of Agrobacterium tumefaciens $\mathrm{C} 58 \mathrm{C} 1$ toward vir-inducing phenolic compounds and soluble factors from monocotyledonous and dicotyledonous plants. J Bacteriol 170:4181-4187.

Boyko A, Matsuoka A, Kovalchuk I (2009). High frequency Agrobacterium tumefaciens-mediated plant transformation induced by ammonium nitrate. Plant Cell Rep 28:737-757.

Chilton MD, Drummond HJ, Merlo DJ, Sciaky D, Montoya AL, Gordon MP, Nester EW (1977). Stable incorporation of plasmid DNA into higher plant cells: The molecular basis of crown gall tumourgenesis. Cell 11:263-271. 
Christey MC, Braun RH (2005). Production of hairy root cultures and transgenic plants by Agrobacterium rhizogenesmediated transformation. Methods Mol Biol 286:47-60.

Cleene MDe, Ley JDe (1976). The host range of crown galls. Bot Rev 42:389-466.

Cleene MDe, Ley JDe (1981). The host range of infectious hairy root. Bot Rev 47:147-194.

Delzer BW, Somers DA, Orf JH (1990). Agrobacterium tumefaciens susceptibility and plant regeneration of 10 soybean genotypes in maturity groups 00 to II. Crop Sci 30:320-322.

Draper J, Scott R, Hamil J (1988). Transformation of dicotyledonous plant cells using the $\mathrm{Ti}$ plasmid of Agrobacterium tumefaciens and the $\mathrm{Ri}$ plasmid of $\mathrm{A}$. rhizogenes. p. 69-160. In: Draper J, Scott R, Armitage P (Eds.). Plant genetic transformation and gene expression, Blackwell Scientific Publications, Oxford.

Gelvin SB (2006). Agrobacterium virulence gene induction. Methods Mol Biol 343:77-84.

Hassan F, Hoque IM, Heiko K, Hans-Jörg J (2007). Transient GUS expression in decapitated lentil embryos. Plant Tiss Cult and Biotech 17:97-102.

Hess KM, Matthew WD, David GL, RolfDJ (1991). Mechanism of phenolic activation of Agrobacterium virulence genes: Development of a specific inhibitor of bacterial sensor/ response systems. Proc Natl Acad Sci 88:7854-7858.

Hodges LD, Cuperus J, Ream W (2004). Agrobacterium rhizogenes galls protein substitutes for Agrobacterium tumefaciens single-standard DNA-binding protein VirE2. J Bacteriol 186:3065-3077.

Hodges LD, Lee LY, McNett H, Gelvin SB, Ream W (2009). The Agrobacterium rhizogenes galls gene encodes two secreted proteins required for genetic transformation of plants. J Bacteriol 191:355-364.

Hopkins DL, Durbin RD (1971). Induction of adventitious roots by culture filtrates of the hairy root bacterium, Agrobacterium rhizogenes. Can J Microbiol 17:1409-1412.

Jian B, Hou W, Wu C, Liu B, Liu W, Song S, Bi Y, Han T (2009). Agrobacterium rhizogenes-mediated tansformation of Superroot-derived Lotus corniculatus plants: a valuable tool for functional genomics. BMC Plant Biol 25:69-78.

Katavic V, Jelaska S, Bakran-Petricioli T, David C (1991). Hosttissue differences in transformation of pumpkin (Cucurbita pepo L.) by Agrobacterium rhizogenes. Plant Cell Tiss Org Cult 24:35-42.

Kenel F, Eady C, Brinch S (2010). Efficient Agrobacterium tumefaciens-mediated transformation and regeneration of garlic (Allium sativum) immature leaf tissue. Plant Cell Rep 29:223-230.

Kong F, Li J, Tan X, Zhang L, Zhang Z, Ma X (2009). A new time-saving transformation system for Brassica napus. Afr J Biotech 8(11):2497-2502.
Kumar V, Sharma A, Prasad BCN, Gururaj HB, Ravishankar GA (2006). Agrobacterium rhizogenes mediated genetic transformation resulting in hairy root formation is enhanced by ultrasonication and acetosyringone treatment. Plant Biotech 9:1-8.

Machado LdeOR, de Andrade GM, Cid LPB, Penchel RM, Brasileiro ACM (1997). Agrobacterium strain specificity and shoot tumour formation in eucalypt (Eucalyptus grandis x E. urophylla). Plant Cell Rep 16:299-303.

Matsumoto S, Machida Y, Takebe I (1986). Rapid method for assaying tumorigenicity of Agrobacterium tumefaciens. Plant Mol Biol Rep 4(1):42-47.

McAfee BJ, White EE, Pelcher LE, Lapp MS (1993). Root induction in pine (Pinus) and Larch (Larix) spp. Using Agrobacterium rhizogenes. Plant Cell Tiss Org Cult 34:5362.

Mihaljevic S, Stipkovic S, Jelaska S (1996). Increase of root induction in Pinus nigra explants using agrobacteria. Plant Cell Rep 15:610-614.

Mohiuddin AKM, Zaliha CA, Chowdhury MKU, Harikrishna K, Suhaimi N (2009). Factors enhancing virulence response of Agrobacteria in cucumber (Cucumis sativus L.). The Agriculturists 7:72-81.

Murashige T, Skoog F (1962). A revised medium for rapid growth and bioassays with tobacco tissue cultures. Physiol Plant 15:473-497.

Parke D, Ornston LN, Nester EW (1987). Chemotaxis to phenolic inducers of virulence genes is constitutively expressed in the absence of the Ti plasmid in Agrobacterium tumefaciens. J Bacteriol 169:5336-5338.

Sarker SR, Hossain M, Shirin F (2009). Precise incubatiob period for the Agrobacterium-mediated transformation efficiency in potato (Solanum tuberosum L.). Plant Tissue Culture and Biotech 19:227-235.

Shaw CH, Ashby AM, Brown A, Royal C, Loake GJ (1988). $\operatorname{Vir} A$ and $\operatorname{vir} G$ are the Ti-plasmid functions required for chemotaxis of Agrobacterium tumefaciens towards acetosyringone. Mol Microbiol 2:413-417.

Smith EF, Townsend CO (1907). A plant tumour of bacterial origin. Science 25:671-673.

Srivastava S, Srivastava AK (2007). Hairy root culture for mass production of high-value secondary metabolites. Crit Rev Biotechnol 27:29-43.

Tabei Y, Kanno T, Nishio T (1991). Regulation and organogenesis and somatic embryogenesis by auxin in melon, Cucumis melo L. Plant Cell Rep 10:225-229.

Trulson A J, Shahin EA (1986) In vitro plant regeneration in the genus Cucumis. Plant Sci 47:35-43

White FF, Taylor BH, Huffman GA, Gordon. MP, Nester EW (1985). Molecular and Genetic analysis of the transferred DNA region of the root-inducing plasmid of Agrobacterium rhizogenes. J Bact 164:33-44. 